\title{
DESEMPENHO DE UM TRATOR OPERANDO EM SOLO COM DIFERENTES TIPOS DE COBERTURA VEGETAL
}

\author{
ANTONIO GABRIEL FILHO ${ }^{1}$, SUEDÊMIO DE L. SILVA ${ }^{2}$, ALCIR J. MODOLO ${ }^{3}$, \\ JOÃO C. M. DA SILVEIRA ${ }^{4}$
}

\begin{abstract}
RESUMO: A eficiência de um trator para desenvolver esforço tratório depende da interação entre o rodado e o solo, envolvendo um complexo conjunto de fatores: característica do rodado, patinagem, transferência de peso do trator, tipo de solo, umidade, estado de compactação, tipo de cobertura do solo, entre outros, que proporcionam diferentes condições de trabalho e interferem no desempenho do trator. Assim, conduziu-se o presente trabalho com o propósito de avaliar alguns desses fatores no desempenho de um trator agrícola, em área coberta com diferentes tipos de cobertura vegetal (aveia, ervilhaca, nabo, aveia e nabo e sem cobertura). O trator foi submetido a cargas por meio do acoplamento a um escarificador de arrasto e instrumentado para a obtenção da força de tração, velocidade de deslocamento, patinagem e consumo de combustível sendo os dados armazenados por meio de um sistema de aquisição de dados. A patinagem foi maior onde a massa de matéria seca era maior, porém não influenciou na potência requerida na barra de tração. A melhor eficiência de tração foi obtida nas parcelas sem cobertura. O coeficiente de tração foi maior nos tratamentos com cobertura de aveia, ervilhaca e nabo comparados com a área sem cobertura. Conclui-se que a cobertura do solo interfere na capacidade do trator em desenvolver esforço para tracionar máquinas e implementos e que o tipo de cobertura pode causar mudanças na patinagem e na eficiência tratória.
\end{abstract}

PALAVRAS-CHAVE: eficiência tratória, potência, patinagem.

\section{TRACTOR PERFORMANCE IN SOIL WITH DIFFERENT TYPES OF PLANTS COVERING}

SUMMARY: The efficiency of a tractor to draft development depends on the interaction among the wheeled and the soil where it moves and it involves a complex group of factors, such as: characteristic of the tire, slip, the tractor weight transfer, soil type, water texture and soil compactation, type of soil covering, among others. The aim of this work was to evaluate the acting of an agricultural tractor in an area covered with different types of plants. It was used five types of soil covering (oat, Vicia sativa, turnip, oat and $V$. sativa together and without cover). A load cell, pulse sensor, flow meters and a system of data acquisition, was used. The slip was larger where the mass of dry matter was larger, even so it didn't influence in the potency requested in the drawbar and in the consumption of fuel. The best traction efficiency was obtained in the portions without covering. The traction coefficient was larger in the treatments with covering of oat, Vicia sativa and turnip, when compared with the area without covering. It is ended that the covering of the soil interferes in the capacity of the tractor in developing effort for pull machines and the covering type can intervene in the slip and tractor efficiency.

KEYWORDS: tractor efficiency, power, slip.

\footnotetext{
${ }^{1}$ Eng ${ }^{\mathrm{o}}$ Agrônomo, Prof. Adjunto, Centro de Ciências Exatas e Tecnológicas, Universidade Estadual do Oeste do Paraná, UNIOESTE, Cascavel - PR , Fone: (0XX45) 220.3199, e-mail: gabriel@unioeste.br

${ }^{2}$ Prof. Adjunto, Centro de Ciências Exatas e Tecnológicas, UNIOESTE, Cascavel - PR.

${ }^{3}$ Aluno do Curso de Doutorado em Engenharia Agrícola - Mecanização Agrícola, UFV, Viçosa - MG.

${ }^{4}$ Aluno do Curso de Mestrado em Engenharia Agrícola UNIOESTE, Cascavel - PR

Recebido pelo Conselho Editorial em: 18-11-2003

Aprovado pelo Conselho Editorial em: 18-10-2004
} 


\section{INTRODUÇÃO}

Na seleção do trator para trabalho no campo, um dos itens mais importantes é a sua capacidade em desenvolver esforço para tracionar as máquinas e implementos agrícolas. Das três principais maneiras de utilizar a potência gerada pelo motor de um trator agrícola, tomada de potência, sistema hidráulico e barra de tração, esta última é a mais utilizada, apesar de ser menos eficiente (LILJEDAHL et al., 1995). Segundo os autores, a transmissão de potência por meio da barra de tração é a maneira mais comum de utilizar o trator porque é versátil. $\mathrm{O}$ principal motivo para o baixo desempenho na barra pode ser atribuído à patinagem, mas outros fatores como: tipo de solo e suas características e propriedades, geometria do trator e a distribuição de peso sobre os rodados, a transferência de peso durante a operação e as características do rodado, entre outros, também interferem na tração.

Na transmissão de potência do motor para a barra de tração, ocorrem perdas que, dependendo das condições de operação do trator, podem atingir níveis bastante comprometedores (MIALHE, 1991). ZOZ (1987) apresentou um diagrama de estimativa da perda de potência nos diferentes mecanismos do trator e diferentes condições de solo, no qual se verifica que, para tratores $4 \times 2$, as perdas podem variar de $20 \%$ em pista de concreto, até $53 \%$ ou mais em solos soltos, pois esses apresentam as condições inadequadas para a tração.

Segundo MIALHE (1991), quando se passa da condição de pista de concreto para terreno agrícola, é justamente na interface rodado-solo onde as perdas de potência se tornam mais críticas. Para YANAI et al. (1999), a tração é influenciada diretamente pelo sistema rodado-solo que varia de acordo com o tipo de solo e pneu. Isso se deve aos fenômenos da patinagem, que provocam a redução no avanço do trator, e ao recalque ou afundamento do rodado no solo que aumenta a resistência ao rolamento (MIALHE, 1991).

O movimento de uma roda pode ser considerado como a variação de três situações distintas: movida, autopropelida ou motriz. Na primeira situação, não há torque no eixo da roda, apenas a ação de uma força externa. Na condição de autopropelida, o torque é suficiente apenas para movimentar a roda sem que haja a tração. Quando a roda desenvolve tração, ela passa a ser considerada motriz (WISMER \& LUTH, 1973). Segundo os autores, a passagem de uma situação para outra ocorre em função do aumento do patinamento, que será positivo quando houver torque na roda e ela desenvolver tração. A capacidade de tração na roda motriz aumenta conforme aumenta o patinamento até um valor máximo.

Conforme MIALHE (1991) e GAMERO \& LANÇAS (1996), a patinagem é a denominação que se dá ao deslizamento entre a superfície da banda de rodagem e o solo, sendo ela um fator determinante para que ocorra a tração. Durante uma operação agrícola, a patinagem pode ser facilmente visualizada pelo movimento giratório das rodas motrizes do trator, com pequeno ou nenhum avanço das mesmas, o que acontece devido à falta de aderência das rodas ao solo (CORRÊA et al., 1999).

A resistência ao rolamento é definida em MIALHE (1980) como a resistência passiva que se opõe ao movimento dos rodados dos tratores e tem origem na deformação provocada no solo e no próprio rodado.

A resistência que um solo oferece aos órgãos ativos das máquinas de preparo do solo depende da área do solo mobilizada que ocorre em função da largura de trabalho do implemento, da profundidade de operação e das características e propriedades físicas estáticas e dinâmicas do solo (GAMERO \& LANÇAS, 1996).

Dentre as propriedades do solo que afetam a eficiência e desempenho operacional de um trator agrícola, podem-se mencionar a textura do solo, as condições de superfície, dependendo de cada tipo de cobertura existente, e a umidade (YANAI et al., 1999). Ainda, segundo os autores, dentre as 
características dos pneus que afetam o desempenho operacional do trator, estão o tipo de construção, a configuração da banda de rodagem, a largura e o diâmetro dos rodados e a carga normal sobre as rodas motrizes.

Entre os fatores que interferem na tração, a condição da superfície do solo é um fator determinante, todavia nos modelos propostos para determinar a eficiência de um trator em desenvolver tração em condições de campo, não se contempla o tipo de cobertura vegetal presente sobre o solo. Destaca-se a importância de conhecer o desempenho sobre cobertura vegetal devido aos grandes avanços em termos de área dos sistemas conservacionistas, entre eles o plantio direto.

A capacidade de um trator em desenvolver tração depende da interação física dos elementos trativos (rodados) com as propriedades físicas do solo. LILJEDAHL et al. (1995) relatam que o desempenho dos rodados no desenvolvimento da tração está relacionado com os parâmetros do solo, presença de resíduo ou cobertura morta, carga sobre o rodado e pressão do rodado.

O modelo proposto por WISMER \& LUTH (1973), desenvolvido com base na análise dimensional, é utilizado para prever o comportamento de tratores em condições de campo. Esse modelo é facilmente empregado no campo para estimar a força de tração de um trator que pode ser obtida determinando-se a resistência do solo à penetração, a carga dinâmica sobre o rodado, a patinagem das rodas que desenvolvem esforço tratório e utilizando as dimensões dos rodados. Segundo ACUÑA et al. (1995), o modelo de Wismer e Luth é adequado para estimar a força de tração na barra do trator.

Em vista do exposto, o objetivo deste trabalho foi analisar o desempenho de um trator agrícola operando sob diferentes tipos de cobertura vegetal .

\section{MATERIAL E MÉTODOS}

O experimento foi conduzido no Núcleo Experimental de Engenharia Agrícola (NEEA), pertencente à Universidade Estadual do Oeste do Paraná, UNIOESTE, localizado no município de

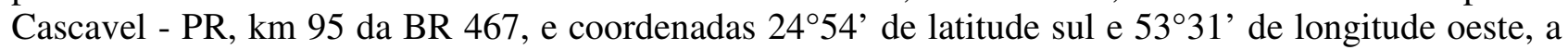
$750 \mathrm{~m}$ de altitude.

A área utilizada para o experimento foi de aproximadamente 0,41 ha, dividida em parcelas com $50 \mathrm{~m}$ de comprimento e três metros de largura. O solo é classificado, de acordo com EMBRAPA (1999), como Latossolo Vermelho distroférico, com textura argilosa e declividade entre 0,0 a $0,03 \mathrm{~m} \mathrm{~m}^{-1}$.

A área experimental era cultivada com o sistema de plantio direto há sete anos, na qual se faziam rotações de culturas de verão com milho e soja, e de inverno com aveia e nabo.

Os equipamentos para a caracterização física do solo utilizados durante os ensaios foram: anéis volumétricos para a determinação da densidade do solo, mesa de tensão para a avaliação da macro e microporosidade e material para a determinação da umidade no solo. As avaliações de densidade, porosidade e umidade foram realizadas conforme EMBRAPA (1997). Também foi utilizado um penetrógrafo para a determinação da resistência do solo à penetração e do índice de cone.

Foram utilizadas sementes de aveia preta (Avena strigosa), nabo forrageiro (Raphanus sativus L.) e ervilhaca (Vicia sativa). A semeadura, realizada com semeadora de fluxo contínuo, ocorreu em maio de 2001, e a dose de sementes utilizada foi $65 \mathrm{~kg} \mathrm{ha}^{-1}$ de aveia, $15 \mathrm{~kg} \mathrm{ha}^{-1}$ de nabo, $60 \mathrm{~kg} \mathrm{ha}^{-1} \mathrm{de}$ ervilhaca, conforme MONEGAT (1991). Cerca de 90 dias após a semeadura, as plantas foram dessecadas com herbicida químico; uma semana depois, foram realizados os ensaios de desempenho do trator.

O ensaio de campo foi realizado utilizando-se de um trator FORD New Holland 7630, aspiração forçada, 4x2 TDA (tração dianteira auxiliar), equipado com rodados traseiros 18.4-34 inflados a 
$370 \mathrm{kPa}$, totalmente lastrado (6.400 kg), submetidos a uma carga estática de $38,2 \mathrm{kN}$ sobre a árvore traseira. Na realização dos ensaios, a TDA permaneceu desligada.

O implemento utilizado para fornecer a resistência na barra de tração foi um escarificador/subsolador de arrasto com cinco hastes de $45 \mathrm{~cm}$ de comprimento e ponteiras de $60 \mathrm{~mm}$ de largura.

Foram instalados no trator os seguintes instrumentos de aquisição de dados:

- Célula de carga com capacidade para $50 \mathrm{kN}$, para medir a força de tração disponível na barra de tração;

- Geradores de impulso para a medir a rotação das rodas motrizes;

- Gerador de impulso com sistema ótico infravermelho para medir a rotação na tomada de potência (TDP);

- Cronômetro para o registro do tempo de cada ensaio, e

- Unidade de radar de efeito "doppler".

Os equipamentos instalados no trator foram conectados a um "Datalogger", modelo CR23X, que realizou as leitura dos sinais emitidos pela célula de carga, sensores de pulso, cronômetro e radar, e armazenou os valores obtidos, sendo os dados posteriormente transferidos a um computador para o processamento.

O experimento constituiu-se de cinco tratamentos definidos em função do tipo de cobertura de solo (aveia, ervilhaca, nabo, nabo e aveia e sem cobertura vegetal), delineados em blocos casualizados, com quatro repetições, totalizando 20 unidades experimentais (parcelas). Os dados obtidos foram submetidos à análise de variância e as médias comparadas pelo teste de Tukey, exceto para as análises de densidade do solo, macro e microporos que foram analisados com uma parcela perdida.

Para a caracterização das condições do solo na camada de 0 a $15 \mathrm{~cm}$ de profundidade, foram determinadas as seguintes propriedades: densidade do solo, porosidade total (macro e microporos) e umidade. As determinações foram realizadas de acordo com os métodos descritos pela EMBRAPA (1997).

A resistência do solo à penetração foi medida até a profundidade de $30 \mathrm{~cm}$, utilizando-se do penetrógrafo em seis pontos distintos das parcelas e avaliados nas profundidades de 2,$5 ; 5,0 ; 7,5 ; 10,0$; 12,$5 ; 15,0 ; 20,0 ; 25,0$ e 30,0 cm. O valor do índice de cone para ser aplicado ao modelo de predição, foi determinado como a média da força necessária para penetrar a ponta cônica do penetrógrafo até à profundidade de $15 \mathrm{~cm}$, conforme relatam WISMER \& LUTH (1973) e LILJEDAHL (1995).

A profundidade de escarificação foi determinada medindo-se, com uma régua graduada em milímetro, a distância entre a superfície do terreno e o fundo do sulco formado pela ponteira das hastes. As medidas foram realizadas para as cinco hastes do escarificador em cada parcela do experimento.

A cobertura vegetal foi avaliada utilizando-se de um quadrado de madeira de $50 \mathrm{x} 50 \mathrm{~cm}$, distribuído aleatoriamente duas vezes em cada parcela. Coletou-se a vegetação da área interna do quadrado que foi seca em estufa a $65^{\circ} \mathrm{C}$ por $48 \mathrm{~h}$ e pesada.

A rotação do motor foi estimada em função da rotação medida na tomada de potência e multiplicada pela razão 1900/540. Essa razão representa a relação de transmissão entre o motor e a TDP, conforme está representado no painel do trator.

Para medir a força de tração média $(\mathrm{Ft})$, foi utilizada a célula de carga, inserida entre o trator e o implemento, nivelada horizontalmente.

A velocidade média real (Vr) de deslocamento do conjunto foi obtida com o radar. 
Para determinar a velocidade teórica, foi considerado o produto do perímetro eficaz e o número de voltas das rodas motrizes nas parcelas, em função do tempo necessário para percorrer cada unidade experimental.

$$
\mathrm{Vt}=\frac{\mathrm{Nr} \mathrm{PE}}{\mathrm{t}}
$$

em que,

$\mathrm{Nr}$ - números de giros da roda motriz;

$\mathrm{PE}$ - perímetro eficaz, $\mathrm{m}$, e

$\mathrm{t}$ - tempo para percorrer $50 \mathrm{~m}$, $\mathrm{s}$.

A patinagem média (S) foi calculada pela eq.(2):

$$
\mathrm{S}=\frac{1-\mathrm{Vr}}{\mathrm{Vt}} 100
$$

em que,

$\mathrm{Vr}$ - velocidade média real medida com o radar, $\mathrm{m} \mathrm{s}^{-1}$, e

$\mathrm{Vt}$ - velocidade média teórica, $\mathrm{m} \mathrm{s}^{-1}$.

O perímetro eficaz foi determinado na própria superfície de trabalho, sendo nula a força de tração na barra, conforme propuseram MIALHE (1991) e CORRÊA et al. (1999).

A potência média disponível na barra de tração $(\mathrm{Pb})$ foi calculada em função da força de tração e da velocidade real de deslocamento do conjunto.

O coeficiente de tração foi calculado da seguinte forma:

$$
\mathrm{Ct}=\frac{\mathrm{Ft}}{\mathrm{We}+(\mathrm{Ft} \mathrm{y} / \mathrm{De})}
$$

em que,

Ft - força de tração média, N;

We - carga estática sobre o rodado, $\mathrm{N}$;

y - altura da barra de tração, m;

De - distância entre eixos, m, e

Wd - carga dinâmica sobre o rodado, $\mathrm{N}$.

A eficiência de tração foi estimada pela equação de WISMER \& LUTH (1973).

$$
\mathrm{Ef}=1-\left\{\frac{\left(\frac{1,2}{\mathrm{Cn}}\right)+0,04}{0,75\left(1-\mathrm{e}^{-0,3 \mathrm{CnS}}\right)}\right\}(1-\mathrm{S})
$$

em que,

e - base dos logaritmos neperianos;

$$
\mathrm{Cn}=\frac{\mathrm{IC} \mathrm{b} \mathrm{d}}{\mathrm{Wd}}
$$

em que,

IC - índice de cone, $\mathrm{N} \mathrm{m}^{-2}$;

b - largura da seção do rodado sem carga, m, e

$\mathrm{d}$ - diâmetro do rodado sem carga, $\mathrm{m}$. 


\section{RESULTADOS E DISCUSSÃO}

A profundidade de escarificação foi mantida próxima dos $30 \mathrm{~cm}$ de profundidade para todos os tratamentos, conforme se observa na Figura 1. Sendo assim, se houve diferença de resistência do solo ao deslocamento das haste entre os tratamentos, deve estar relacionada às alterações nas propriedades físicas do solo.

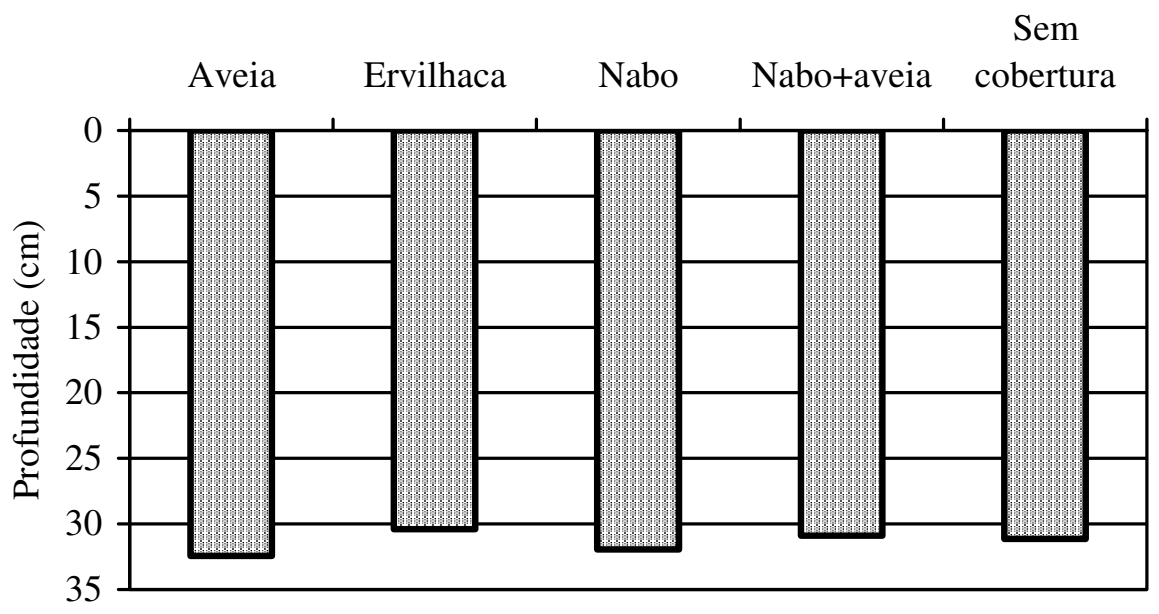

FIGURA 1. Profundidade média de escarificação obtida durante os ensaios.

A resistência do solo à penetração foi mais acentuada na camada de 10 a $15 \mathrm{~cm}$, como se pode observar na Figura 2.

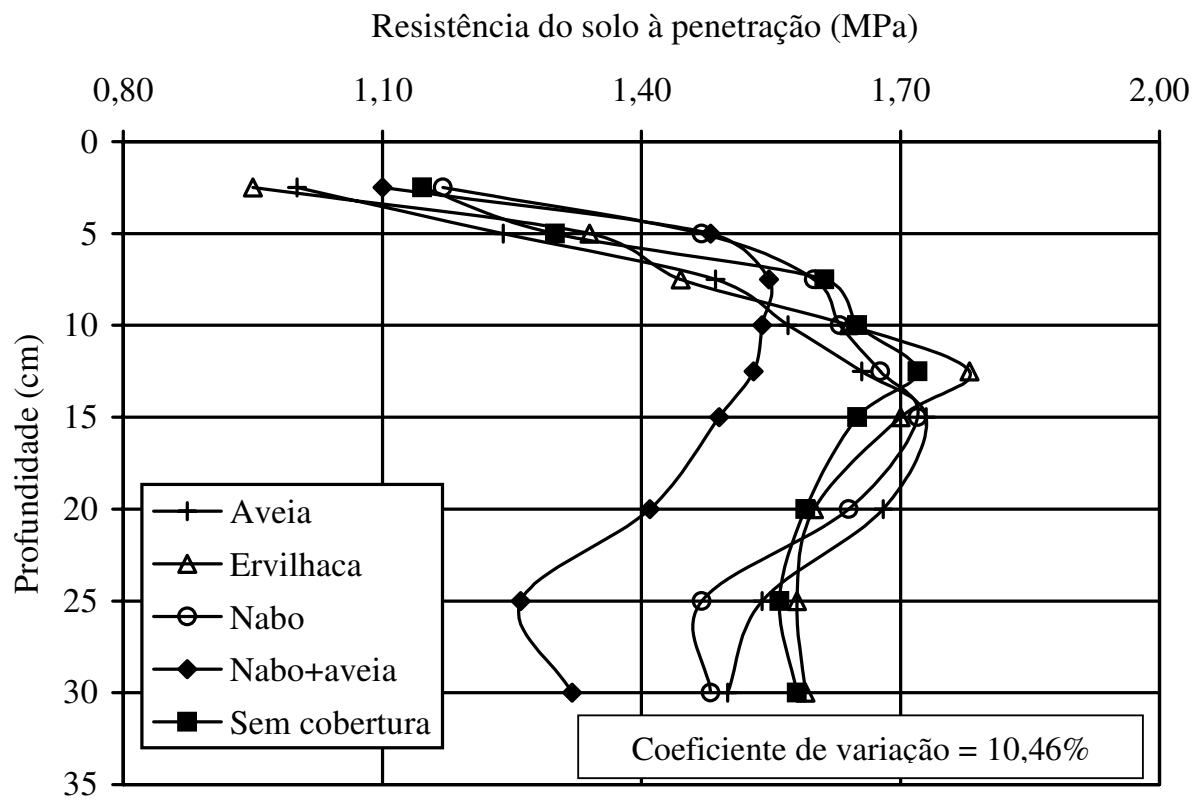

FIGURA 2. Curvas de resistência do solo à penetração em função da profundidade.

Entre as coberturas e comparando-as com a testemunha, nas camadas analisadas, o coeficiente de variação obtido foi relativamente baixo (Figura 2), mostrando uniformidade dos valores. As propriedades físicas do solo estudadas (densidade, umidade, macro e microporos) não apresentaram diferenças significativas (Tabela 1). As plantas de cobertura escolhidas para este trabalho produziram quantidades diferentes de massa seca, conforme se observa na Tabela 1, pois o nabo e o consórcio 
nabo e aveia diferenciaram-se significativamente da ervilhaca, sendo que a aveia não foi estatisticamente diferente dos outros tratamentos com cobertura. Observa-se também, na Tabela 1, que, por meio do coeficiente de variação, a dispersão dos dados de umidade foi baixa e, para a densidade do solo, macroporosidade e microporosidade foram normais, conforme CAMPOS (1984). A capacidade de um conjunto motomecanizado em desenvolver o esforço tratório é um fator que está relacionado à variabilidade das propriedades físicas do solo (GRISSO et al., 1996) e a utilização de espécies vegetais para cobrir o solo pode alterar essas propriedades por meio do sistema radicular.

TABELA 1. Valores médios da densidade do solo (DS), umidade (Um), macro (Ma) e microporos (Mi), matéria seca (MS), coeficiente de variação e teste $F$ para os tratamentos.

\begin{tabular}{|c|c|c|c|c|c|c|c|}
\hline \multirow{2}{*}{ Determinações } & \multicolumn{5}{|c|}{ Tratamentos } & \multirow{2}{*}{$\begin{array}{l}\text { C.V. } \\
(\%)\end{array}$} & \multirow{2}{*}{$\mathrm{F}$} \\
\hline & Aveia & Ervilhaca & Nabo & Nabo/Aveia & Sem cob. & & \\
\hline$\overline{\mathrm{DS}}\left(\mathrm{kg} \mathrm{dm}^{-3}\right)$ & 1,31 & 1,30 & 1,32 & 1,35 & 1,28 & 10,32 & $3,45 \mathrm{~ns}$ \\
\hline $\operatorname{Um}\left(\mathrm{kg} \mathrm{kg}^{-1}\right)$ & 0,26 & 0,26 & 0,28 & 0,26 & 0,26 & 3,88 & $2,70 \mathrm{~ns}$ \\
\hline $\mathrm{Ma}\left(\mathrm{m} \mathrm{m}^{-3}\right)$ & 0,17 & 0,15 & 0,16 & 0,16 & 0,20 & 16,50 & $0,32 \mathrm{~ns}$ \\
\hline $\operatorname{Mi}\left(\mathrm{m} \mathrm{m}^{-3}\right)$ & 0,47 & 0,48 & 0,46 & 0,42 & 0,52 & 11,64 & $2,61 \mathrm{~ns}$ \\
\hline $\operatorname{MS}\left(\mathrm{kg} \mathrm{ha}^{-1}\right)$ & $4.082 \mathrm{a}^{*}$ & $2.241 \mathrm{~b}$ & $5.497 \mathrm{a}$ & $4.964 \mathrm{a}$ & 0 & 23,31 & $12,67 * *$ \\
\hline
\end{tabular}

* Médias seguidas por letras iguais na linha não diferiram entre si, pelo teste de Tukey $(\mathrm{P}>0,05)$. ns $=$ não significativo, $* *$ significativo a $1 \%$.

$\mathrm{Na}$ Tabela 2, apresentam-se os valores médios da rotação do motor, força de tração, velocidade e patinagem. A rotação do motor foi mantida homogênea, e a variação entre os tratamentos não foi estatisticamente significativa. A força de tração requerida na barra foi maior nos tratamentos com cobertura de aveia, ervilhaca e nabo, comparados com a testemunha, área sem cobertura. A velocidade de deslocamento variou significativamente entre os tratamentos, sendo menor na aveia, a qual não diferiu apenas do tratamento composto pelo nabo mais a aveia; este último diferiu do tratamento sem cobertura. O patinamento também variou entre os tratamentos, sendo menor na área sem cobertura comparada com a área coberta com aveia, que, por sua vez, não diferiu somente da área com nabo.

TABELA 2. Valores médios da rotação do motor (RM), força de tração (Ft), velocidade (Vr) e patinagem $(\mathrm{S})$ obtidos em função dos tratamentos realizados com coberturas vegetais.

\begin{tabular}{lcccc}
\hline Tratamentos & RM $(\mathrm{rpm})$ & $\mathrm{Ft}(\mathrm{kN})$ & $\operatorname{Vr}\left(\mathrm{km} \mathrm{h}^{-1}\right)$ & $\mathrm{S}(\%)$ \\
\hline Aveia & $1.923 \mathrm{a}$ & $29,37 \mathrm{a}$ & $3,37 \mathrm{c}$ & $20,74 \mathrm{a}$ \\
Ervilhaca & $1.941 \mathrm{a}$ & $28,37 \mathrm{a}$ & $3,59 \mathrm{ab}$ & $16,60 \mathrm{bc}$ \\
Nabo & $1.930 \mathrm{a}$ & $29,19 \mathrm{a}$ & $3,55 \mathrm{ab}$ & $17,18 \mathrm{abc}$ \\
Nabo+Aveia & $1.916 \mathrm{a}$ & $27,95 \mathrm{a}$ & $3,52 \mathrm{bc}$ & $17,43 \mathrm{bc}$ \\
Sem cobertura & $1.932 \mathrm{a}$ & $25,00 \mathrm{~b}$ & $3,71 \mathrm{a}$ & $13,60 \mathrm{c}$ \\
\hline Média & $1.928,35$ & 27,98 & 3,55 & 17,11 \\
C.V. $(\%)$ & 0,87 & 3,92 & 1,93 & 9,38 \\
DMS & 37,66 & 2,47 & 0,15 & 3,63 \\
\hline
\end{tabular}

Médias seguidas por letras iguais na coluna não diferiram entre si, pelo teste de Tukey $(\mathrm{P}>0,05)$.

Na Tabela 3, estão representados os valores médios calculados de potência na barra, coeficiente de tração, índice Cn e a eficiência tratória estimada pela equação de Wismer e Luth.

A potência na barra de tração foi estatisticamente menor nas áreas sem cobertura comparadas com as áreas cobertas com aveia ou ervilhaca. Em relação aos valores de coeficiente de tração computados, observa-se distribuição semelhante com a força de tração, com as mesmas variâncias entre os tratamentos. A eficiência tratória foi menor na aveia, não tendo diferença dessa em relação ao nabo e aveia cultivados juntos. Melhor eficiência de tração foi obtida nas parcelas em que foi cultivado 
o nabo; contudo, estatisticamente, a testemunha (área sem cobertura), a ervilhaca, o nabo e a aveia apresentaram resultados semelhantes. Comparando a coluna de eficiência (Tabela 3) com a de patinamento (Tabela 2), observa-se que, nos tratamentos em que o patinamento foi maior, a eficiência foi menor, o que está de acordo com as observações de vários autores, entre os quais, WISMER \& LUTH (1973), ZOZ (1987) e MAZIERO et al. (1997). Os resultados da exigência tratória expressa pelo coeficiente de tração ou eficiência tratória corroboram com as afirmações de WISMER \& LUTH (1973), LILJEDAHL et al. (1995), MIALHE (1996), CORRÊA et al. (1999) e YANAI et al. (1999), entre outros, de que a tração depende da interação entre o rodado e o solo, em que a cobertura interfere na capacidade do trator em desenvolver a tração.

TABELA 3. Valores médios da potência na barra $(\mathrm{Pb})$, coeficiente de tração $(\mathrm{Ct})$, índice $\mathrm{Cn}$ e eficiência tratória (Ef) obtidos em função dos tratamentos realizados com coberturas vegetais.

\begin{tabular}{lcccc}
\hline Tratamentos & $\mathrm{Pb}(\mathrm{kW})$ & $\mathrm{Ct}(\%)$ & $\mathrm{Cn}$ & $\mathrm{Ef}(\%)$ \\
\hline Aveia & $27,48 \mathrm{ab}$ & $77,25 \mathrm{a}$ & $27,62 \mathrm{~b}$ & $68,07 \mathrm{~b}$ \\
Ervilhaca & $28,23 \mathrm{ab}$ & $75,00 \mathrm{a}$ & $30,53 \mathrm{ab}$ & $71,65 \mathrm{a}$ \\
Nabo & $28,74 \mathrm{a}$ & $76,88 \mathrm{a}$ & $36,67 \mathrm{a}$ & $73,27 \mathrm{a}$ \\
Nabo+Aveia & $27,32 \mathrm{a}$ & $74,10 \mathrm{a}$ & $28,30 \mathrm{~b}$ & $70,68 \mathrm{ab}$ \\
Testemunha & $25,73 \mathrm{~b}$ & $67,30 \mathrm{~b}$ & $27,90 \mathrm{~b}$ & $72,08 \mathrm{a}$ \\
\hline Média & 27,50 & 71,15 & 30,20 & 74,10 \\
CV $(\%)$ & 4,09 & 1,97 & 9,81 & 3,37 \\
DMS & 2,54 & 3,14 & 6,30 & 5,64 \\
\hline
\end{tabular}

*Médias seguidas por letras iguais na coluna não diferiram entre si, pelo teste de Tukey $(\mathrm{P}>0,05)$.

\section{CONCLUSÕES}

O uso de planta de cobertura não alterou as propriedades físicas do solo de forma significativa, mas a variabilidade dessas propriedades pode interferir na capacidade do trator em tracionar máquina ou implemento agrícola.

A maior quantidade de matéria seca na superfície do solo tende a elevar os índices de patinamento.

Em áreas onde existe cobertura vegetal, há alteração na interação do rodado com o solo, e a capacidade do trator em desenvolver a tração é afetada.

\section{REFERÊNCIAS}

ACUÑA, R.R.D.; MANTOVANI, E.C.; MARTYN, P.J.; BERTAUX,S. Comparação do coeficiente de tração e da eficiência tratória de um trator agrícola obtidos pela equação de Wismer e Luth e por ensaios de campo. Pesquisa Agropecuária Brasileira, Brasília, v.30, n.4 p.523-30, 1995.

CAMPOS, H. Estatística aplicada à experimentação com cana-de-açúcar. São Paulo: FEALQ, 1984. $292 \mathrm{p}$.

CORRÊA, I.M.; MAZIERO, J.V.G.; YANAI, K; LOPES, A. Técnicas de determinação da patinagem das rodas motrizes de tratores agrícolas. Campinas: Instituto Agronômico, 1999. 15 p. (Boletim Técnico, 179).

EMPRESA BRASILEIRA DE PESQUISA AGROPECUÁRIA. Manual de métodos de análise de solo. 2. ed. Rio de Janeiro, 1997. 212 p.

EMPRESA BRASILEIRA DE PESQUISA AGROPECUÁRIA. Sistema brasileiro de classificação de solos. Brasília, 1999. 412 p. 
GAMERO, C.A.; LANÇAS, K.P. Ensaio e certificação das máquinas de mobilização periódica do solo. In: MIALHE, L.G. Máquinas agrícolas: ensaio e certificação. Piracicaba: CNPq-PADCT/TIBFEALQ, 1996. p.463-514.

GISSO, R.D.; YASIN, M.; KOCHER, M.F. Tillage implement force operating in silt clay loam. Transaction of the ASAE, St. Joseph, v.39, n.6, 1996, p.1977-82.

LILJEDAHL, J.B.; CARLETON, W.M.; TURNQUIST, P.K.; SMITH, D.W. Traction. In:

Traction and their power units. Connecticut: Avi Publish Company, n.2, 1995. p.219-26.

MAZIERO, J.V.G.; MIALHE, L.G.; CORRÊA, I.M.; YANAY, D.; MENEZES, J.F. Efeito da patinagem da roda motriz de um trator agrícola na compactação do solo. Bragantia, Campinas, v.56, n.1, p.1-11, 1997.

MIALHE, L.G. Gerência de sistema tratorizado vs operação otimizada de tratores. Piracicaba: ESALQ/USP, 1991. 30 p.

MIALHE, L.G. Máquinas motoras na agricultura. São Paulo: EPUEDUSP, 1980. v.2, 345 p.

MIALHE, L.G. Ensaio e certificação de tratores. In: Piracicaba: CNPq-PADCT/TIB-FEALQ, 1996. p.385-462. Máquinas agrícolas: ensaio e certificação.

MONEGAT, C. Plantas de cobertura do solo: características e manejo em pequenas propriedades. Chapecó: Ed. do Autor,1991. 337 p.

WISMER, R.D.; LUTH, H.J. Off-road traction prediction for wheeled vehicles. Transactions of the ASAE, St. Joseph, v.17, n.1, p.8-14, 1973.

YANAI, K.; SILVEIRA, G.M.; LANÇAS, K.P.; CORRÊA. I.M.; MAZIERO, J.V.G. Desempenho operacional de trator com e sem acionamento da tração dianteira auxiliar. Pesquisa Agropecuária Brasileira, Brasília, v.34, n.8, p.1427-34,1999.

ZOZ, F.M. Predicting tractor field performance (updated). St. Joseph: ASAE, 1987. p.15. (ASAE Paper, 87-1623). 